\title{
Switching from an inclining to a zero-level unemployment benefit profile: Good for work incentives?
}

\author{
Bart Cockx, Koen Declercq, Muriel Dejemeppe, Leda Inga and Bruno Van der Linden ${ }^{1}$
}

March 9, 2020

\begin{abstract}
This paper evaluates the impact on the transition to work of a policy reform in Belgium that restricted the access to a specific unemployment insurance scheme for young labor market entrants. This scheme entitles youths with no or little labor market experience to unemployment benefits after a waiting period of one year. As of 2015, the Belgian government unexpectedly scrapped benefit eligibility for youths who start the waiting period at the age of 24 or older. The reform implied a change from an inclining to a flat rate (zero-level) benefit profile. We use a difference-in-differences approach to identify the causal impact of this reform on fresh university graduates. Our main finding is that this reform only increases the transition to very short-lived jobs.
\end{abstract}

JEL codes: J64, J65, J68

Keywords: Youth unemployment, Unemployment insurance, Policy evaluation, Difference-indifferences

\footnotetext{
1 Bart Cockx: Department of Economics, Ghent University; CESifo, Munich; IZA, Bonn; ROA, Maastricht University (bart.cockx@ugent.be), Koen Declercq: Leuven Economics of Education Research, KU Leuven; IRES/LIDAM, UCLouvain and FNRS (koen.declercq@kuleuven.be), Muriel Dejemeppe: IRES/LIDAM, UCLouvain and GLO (muriel.dejemeppe@uclouvain.be), Leda Inga: Centre for Research in Economics and Management, University of Luxembourg, Bruno Van der Linden: IRES/LIDAM, UCLouvain; FNRS; CESifo, Munich; IZA, Bonn (bruno.vanderlinden@uclouvain.be). We thank the editor, two anonymous referees and the review committee of the National Bank of Belgium for their valuable comments. We are grateful to the National Bank of Belgium for funding as well as FOREM and VDAB for providing the data. We thank the participants to the EALE 2019 and COMPIE 2018 conference for their comments and participants at seminars at UCLouvain and Ghent University. The usual disclaimer applies.
} 


\section{Introduction}

Developed countries usually provide some form of social protection to financially support young labor market entrants in case they do not directly find insurable employment. In most countries this consists in a means-tested welfare benefit, but in some others freshly educated youths are entitled to unemployment insurance (UI). Such a scheme is often accompanied by strong eligibility conditions to contain moral hazard costs. In Australia and New Zealand $\mathrm{UI}$ is provided immediately upon registration as job seeker, but imposes very strict job search requirements. In Belgium, Denmark and Luxembourg entitlement to $\mathrm{UI}$ is subject to less stringent job search obligations (Langenbucher, 2015), but is postponed by a waiting period. ${ }^{2}$ In Sweden, until 2007 high school graduates were entitled to unemployment benefits (UB) only from age 20 onwards (von Buxhoeveden, 2019).

In Belgium, the focus of our analysis, there is a one-year waiting period between the time that youths enter the job market and the moment they become eligible for $\mathrm{UI}$ benefits. This aims at keeping work incentives high in the school-to-work transition. As of 2015, the Belgian government unexpectedly scrapped the entitlement to these benefits for youths who start the waiting period at the age of 24 or older. With an average age of graduation from master programs slightly above 24 in Belgium, this decision affected in particular master's graduates. In this paper we empirically test whether this reform affected their work incentives within one year and a half following labor market entry. The way the reform has been implemented offers a unique natural experiment to study this question. The 24-yearold graduates who registered for the first time as unemployed job seekers in 2014 were informed by surprise in January 2015 that they were no longer entitled to $\mathrm{UI}$ at the end of their waiting period. By contrast, graduates aged 23 at first registration in 2014 remained entitled. This therefore naturally allows to evaluate the effects of the reform on employment outcomes in a difference-in-differences approach.

Before 2015, UI for young labor market entrants in Belgium displayed an unusual inclining benefit profile. In such a setting, work incentives are maximal at the start of the zero-benefit waiting period. Later on, as one approaches the end of this period, standard job search theory (Mortensen, 1977 and van den Berg, 1990) predicts that homogeneous forward-looking agents progressively decrease search effort and increase their reservation wage. These behavioral reactions result in decreasing job finding rates, better job matches and higher earnings. The 2015 reform that completely abolishes the entitlement to this inclining profile is therefore expected to reverse these predictions. Relative to the counterfactual of no policy reform, job finding is expected to gradually increase and the quality of found jobs to decrease as the end of the waiting period is approached.

There is ample empirical evidence that reducing the generosity of social benefits positively impacts job finding and that recipients anticipate by accelerating their transitions to employment well before benefits exhaust (see for a survey Tatsiramos and Van Ours, 2014, or Schmieder and von Wachter, 2016). There is, however, to the best of our knowledge, not any evidence on the impact on job finding of a change from an increasing profile of UI benefits to a flat rate (zero-level) benefit profile. Based on the arguments of Kolsrud et al. (2018), we may actually expect that such a change has only small positive effects on job finding rates. Dynamic sorting and negative duration dependence in job finding rates imply that youths who are sensitive to monetary incentives may already have left unemployment before the prospect of losing entitlement to UI starts to play a role on behavior. In the Belgian UI scheme for youth, no benefits are paid-out at the start, so that these incentives are very strong initially. Hence, the dynamic sorting will progress at a faster rate than in regular UI. To this can be added the

\footnotetext{
2 Based on age and educational attainment, young labor market entrants in Luxembourg are eligible for unemployment benefits after a waiting period of six months (Luxembourg Employment Agency, 2020). In Denmark, all labor market entrants who join an unemployment fund within two weeks after graduation can immediately obtain unemployment benefits. Those who register after this two-week deadline, are paid out unemployment benefits only after one year (A-Kasser, 2019).
} 
predictions of the calibrated life-cycle model of Michelacci and Ruffo (2015). They conclude that moral hazard is less an issue for youth than for prime aged workers because the young want to be employed anyway as to improve life-time career prospects.

Researchers have not only studied the impact of UI generosity on job finding. There is also ample but mixed evidence about its effect on job quality. ${ }^{3}$ Nekoei and Weber (2017) explain why it is so in the case of the impact of an extension of benefit duration. While an extension raises the reservation wage, the more selective acceptance behavior implies that individuals remain longer unemployed which in turn reduces job quality. This lower quality can be caused by the employers' screening of job applicants based on unemployment duration (Kroft et al., 2013) or by a reduced selectivity of long-term unemployed as a consequence of liquidity constraints (Chetty, 2008; Card et al., 2007). The reform analyzed in this paper may have a similar ambiguous effect on job quality. On the one hand, the prospect of not qualifying for UB is likely to induce many unemployed youths to become less selective in their job acceptance decision. On the other hand, the reform may also induce young graduates to find jobs earlier in the unemployment spell when higher quality jobs are available (Lindner and Reizer, 2019). The last channel requires, however, that the reform effectively induces youths to accelerate job finding early in the waiting period, which we do not expect given the length of this period. The first channel should therefore dominate and drive a negative effect of the reform on job quality.

This is not the first study of the behavioral effects of waiting periods for UI or welfare benefits. However, the existing papers have focused on the effect of introducing such qualifying periods (Bolhaar et al., 2019) or extending their duration (Cockx and Van Belle, 2019). Other research has studied instead the effect on work incentives of receiving benefit payments after a period of no-pay status (Bargain and Doorley, 2011; von Buxhoeveden, 2019). In contrast to these studies, we contribute to the literature by analyzing the impact on work incentives of abolishing the entitlement to $\mathrm{UI}$ benefits when a waiting period is completed. As we will show in this study, the length of such period is an important determinant of employment responses to such a scheme.

Our analysis uses administrative population data of all recent master's graduates who registered for the first time as unemployed job seeker at the regional Public Employment Services (PES) between 2011 and 2014. For privacy reasons we only have access to data grouped by age and period of registration. Since not all employment outcomes are measured in the same way across regions, the analysis is performed separately for the two main regions of Belgium: Flanders and Wallonia. Cumulative job finding rates are observed six, twelve and eighteen months after registration. The rates measured after six and twelve months are used to study the behavioral anticipation of the prospect of losing entitlement to $\mathrm{UI}$, while the one measured after eighteen months allows to detect the (additional) ex-post effect of actually losing benefit eligibility. In Wallonia job finding includes jobs lasting as short as one day, while in Flanders a job transition is registered only to the extent it is still ongoing at the end of the month. To estimate the effect on short-lived jobs in this region, we therefore use an indicator of transitions to temporary help agency work (temp jobs for short) that the Flemish PES registers separately. Because there may be a trade-off between rapid job finding and lasting integration on the job market, our range of outcomes also includes the probability of being employed measured at the same time horizons as the job finding rate.

The empirical results deliver two main messages. First, they provide clear evidence that the prospect of losing UI eligibility increases the transition to very short-lived jobs. In Flanders, in the absence of the policy reform, $9.0 \%$ (resp. $12.1 \%$ ) of the 24 -year-old master's graduates registered as job seekers would

\footnotetext{
3 Some studies find positive effects of benefit extensions in terms of wages or job stability (e.g. Tatsiramos, 2009, Centeno and Novo, 2009, and Nekoei and Weber, 2015). Others find negative or no effects (e.g. Lalive, 2007, Caliendo et al., 2013, Card et al., 2007, van Ours and Vodopivec, 2006, Le Barbanchon, 2016, and Schmieder et al., 2016). In a recent study, de Groot and van der Klaauw (2019) show modest negative effects of reducing the UI entitlement period on job quality.
} 
have found a temp job within 6 (resp. 12) months after registration. The policy reform caused a significant increase of this fraction by 3.3 (3.7) percentage points. Effects of a similar order of magnitude are estimated in Wallonia on cumulative transitions to employment lasting at least one day, although less precisely. There is, however, no evidence of an additional effect of the policy reform when the eligibility loss has become a tangible reality, i.e. one year and a half after registration. Second, when we consider the effects on transitions to more stable jobs (ongoing at the end of the month) and on employment probabilities, the impacts are at all moments of observation small and statistically not significantly different from zero. In sum, our findings suggest that the reform has only accelerated transitions to short-term labor contracts which did not serve as a stepping stone to stable employment.

The remainder of this paper is organized as follows. Section 2 summarizes the institutional context, the policy reform and the natural experiment it entails. Section 3 takes a first look at our dataset and provides the exact definition of the employment outcomes of interest. Section 4 discusses the methodology and section 5 presents the results. Section 6 ends with some concluding remarks.

\section{Institutional framework}

In this section we first explain the pre-reform eligibility conditions for unemployment benefits (UB) targeted to people who become unemployed on leaving education. Subsequently, we discuss the policy reform of 2015 that is evaluated in this study.

\subsection{The Activation Allowance}

In Belgium, young labor market entrants are eligible for non-means-tested UI based on age and weak educational requirements. This unemployment benefit is called the "activation allowance". It aims at supporting young unemployed job seekers who are or become unemployed one year after their first entry in the labor market and who are not eligible for regular $\mathrm{UI}$ benefits, because they did not contribute sufficiently: this requires proof of at least one year of full-time employment. The one-year waiting period starts either at the first registration as job seeker at the regional PES or at the start of the first employment spell, whichever is earlier. Once the waiting period ends, the job seeker can start claiming UI benefits. Before the policy reform of 2015, job seekers were entitled to the activation allowance if they were younger than 30 when they claimed this benefit for the first time. Even high school dropouts were eligible provided that they spent sufficient time in school. Periods of unemployment and employment reduce the waiting period, but periods of inactivity, such as sickness, resumed education or participation in long-lasting (i.e. $>9$ months) training programs, extend it.

During the waiting period, the regional PES assists the unemployed in their job search by providing intermediation services, counseling or training programs. The PES is also in charge of job search monitoring. Compared to other OECD countries, where the monitoring of job search effort often takes place at regular intervals (monthly or even weekly) (Langenbucher, 2015), it occurs much later and more infrequently in Belgium. It is only as from the $7^{\text {th }}$ and $11^{\text {th }}$ month of the waiting period that job seekers are interviewed in relation to their job search activities. To be eligible for the activation allowance at the end of the waiting period they must prove sufficient search effort at these two moments. If they do not, this period is prolonged until they do. ${ }^{4}$

\footnotetext{
${ }^{4}$ In case of a negative evaluation by the caseworker, individuals must request to be interviewed again. This new interview is carried out six months after the negative evaluation, at the earliest. Nonetheless, the percentage of individuals who get a negative evaluation at the scheduled interviews is very small, between $4 \%$ and $8 \%$ (Onem, 2013, 2014).
} 
The activation allowance is a flat rate non-means tested benefit, the level of which depends on age and family status. In 2015, young entrants to the labor market who live on their own without dependents were entitled to a monthly benefit of 818 euro above the age of 21 . In Belgium, most unemployed youths still live with their parents (Cockx and Van Belle, 2019). In that case they were paid out a monthly allowance of 425 euro as cohabitant. Since January 2012, the activation allowance is time limited with as general rule a maximum duration of 3 years. Before 2012, there was no time limit.

Individuals with insufficient income are eligible for means-tested welfare benefits. In 2015 the level of these benefits amounted to 556 euro per month for cohabitants and 834 euro for singles. Since the majority of unemployed youths who leave education continue living with their parents, they generally do not qualify for these welfare benefits, because the means-test applies to the household income. Only if they live alone (and only a minority does) or their parents have a too low income, they may claim these benefits. If they do, they will most likely already do so during the waiting period. In that case the entitlement to the activation allowance does not affect their financial resources. Even if figures on welfare take-up among the population targeted in our study are not known, it is likely to be very small. In 2011 , only $2.2 \%$ of students aged $18-24$ claimed welfare benefits (IDD, 2012, p. 4).

\subsection{The policy reform as a natural experiment}

On December 31 2014, the Belgian government signed an agreement to reinforce the eligibility conditions for the activation allowance. Officially, the aim of this reform was to cope with the perverse incentives of this allowance for job search incentives of youths, but the budgetary savings that came along with it were certainly also part of the motivation of its implementation. As of January 12015 , youths aged 25 or more at the time of the first claim can no longer benefit from the activation allowance. Given the one-year waiting period, students must enter the labor market before their $24^{\text {th }}$ anniversary to retain eligibility. The reform therefore changed the benefit profile from inclining to a flat rate one (at zero) for youths stopping to study at age 24 or older. Youths who had already started receiving the activation allowance before 2015 were not affected by the reform.

In this paper we evaluate this reform by using a natural experiment created by the particular timing of the reform. Even if the principle of the reform was announced in the government agreement of October 2014, it had been hardly, if at all, discussed in press before its implementation. Moreover, the timing came as a complete surprise as the decision was communicated after a ministerial council on December 31, 2014 without having been announced as an item on the agenda. Hence, on January 1 2015, job seekers aged 24 or older who had started their waiting period in 2014 were by surprise informed that they were no longer entitled to the activation allowance at the end of this one-year period, unlike younger age groups.

Since in Belgium the average master student who graduates from university is slightly older than 24, the 2015 reform mostly affected these university graduates. We will therefore focus on this group in our empirical evaluation of the reform. Students can graduate from master programs in July (in case they succeed for all courses during the regular exam period) or in September (in case they failed some courses during the regular exam period and had to retake some courses in August/September).

Figure 1 illustrates the entitlement trajectory to the activation allowance for students who after graduation from university in July 2014, registered as job seeker at the PES in August 2014 at the age of 23 (our control group) or at the age of 24 (our treatment group). For the sake of simplicity, we assume that they did not immediately enter employment after graduation. The younger age group (Panel A) became eligible for the activation allowance if they were unemployed at the end of the oneyear waiting period in August 2015, conditional upon two successful evaluations of search effort. At the start of the waiting period, the older age group (Panel B) expected to be eligible for the activation 
allowance as from August 2015 if unemployed. On January 1 2015, these job seekers were suddenly informed that they would no longer be eligible for this allowance after this period has elapsed.

As a consequence of this reform, unemployed youths aged 24 or older were no longer required to attend the two interviews with a caseworker from the PES to provide proof of their job search effort. The suppression of the monitoring interviews could lead to behavioral reactions in the opposite direction than those expected with the prospect of being disqualified from the activation allowance. With our data, we are not able to disentangle these two effects. However, as mentioned in Section 2.1, with only two evaluations of job search effort over a year, the Belgian monitoring scheme is lenient. Hence, its suppression has most likely a negligible impact on job search behavior in particular compared to the withdrawal of the entitlement to the activation allowance. ${ }^{5}$ This is consistent with the evidence in Cockx et al. (2018) about the impact of the monitoring of job-search effort in Belgium on unemployed people aged between 25 and 30 .

Figure 1: Trajectory of entitlement to the activation allowance (in month/year)

Panel A: 23-year-old job seeker

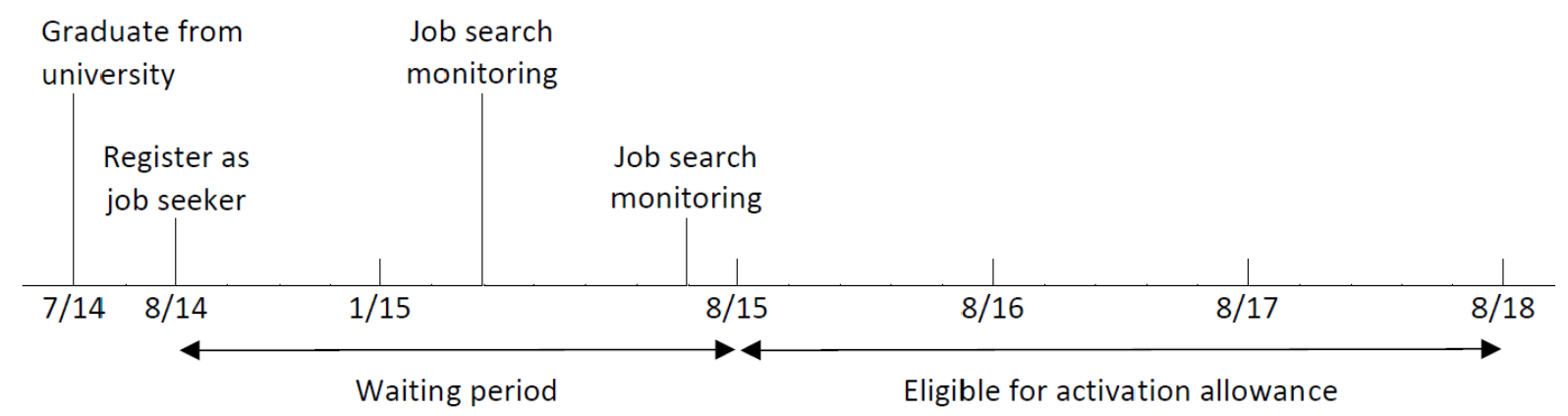

Panel B: 24-year-old job seeker

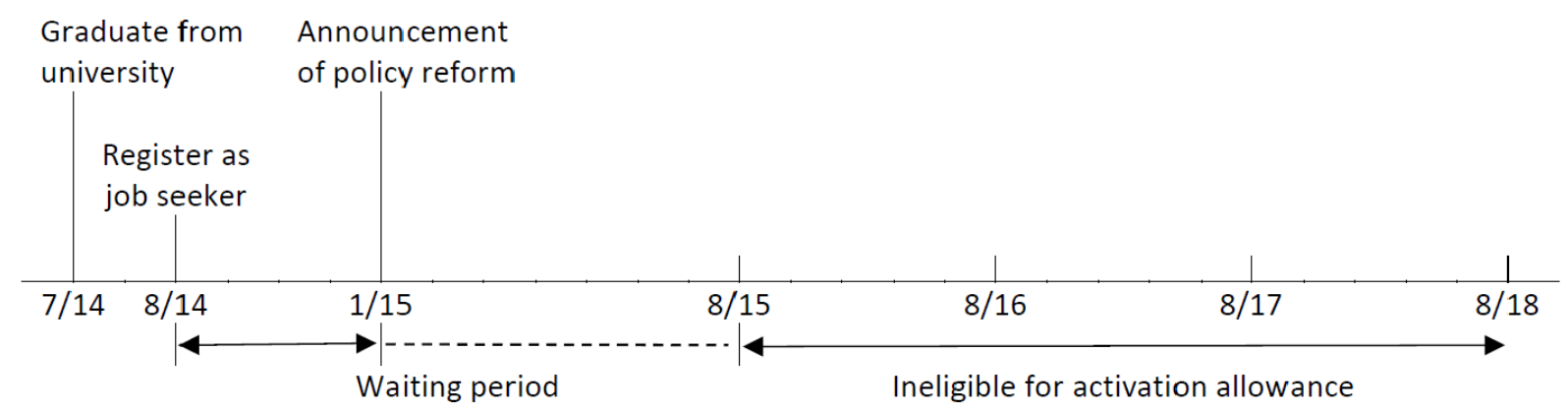

Notes: Trajectory of entitlement to the activation allowance for a 23- and 24-year-old job seeker. Age is measured at the moment of registration as a job seeker.

The Belgian government did not only restrict access to the activation allowance for youths starting their waiting period after their $24^{\text {th }}$ birthday, but also for high school dropouts. Starting from September 1 2015, school-leavers who do not successfully complete the sixth year of high school cannot claim the activation allowance before age 21 . The aim of this reform was to encourage young

\footnotetext{
${ }^{5}$ We can further argue that it is unlikely that there is any measurable effect of the suppression of job search monitoring at the first time horizon considered in our study, i.e. six months after registration as job seeker (unless treated job seekers anticipate this suppression by decreasing their search effort). This is because the first evaluation of job search activities would have taken place not earlier than in the seventh month of the waiting period and possibly later as a consequence of administrative delays.
} 
people to attain a high school degree, as this enhances their chances on the labor market. Since high school dropouts regain entitlement to the activation allowance from age 21 onwards, the reforms had more severe consequences for individuals leaving education at the age of 24 or older because they faced a permanent loss of the activation allowance. This is why we focus only on the policy reform for the older age group in this paper. ${ }^{6}$

\section{Data}

The empirical analysis is based on administrative grouped population data of recent university graduates who registered for the first time at the PES as unemployed job seekers between 2011 and 2014. This data was readily provided by the regional PES of the two largest regions in Belgium: VDAB in Flanders and FOREM in Wallonia. The data are grouped by year of registration, period of registration within the year and age. Age is measured in years at the moment of registration at the PES. For privacy reasons, the data do not contain other characteristics of job seekers.

Our first outcome of interest is the job finding rate measured 6, 12 and 18 months after registration. This (group-level) outcome is defined as the cumulative share of unemployed individuals who found a job within 6, 12 and 18 months. This outcome ignores transitions to very short employment spells that start and end within the same month, because a transition is counted only to the extent that the individual is still employed at the end of the month. To test whether the reform affected the transition to more durable employment or only to very short-term jobs, we also consider two alternative measures of job finding. Due to the different registration methods in the regional PES, we have to rely here on a different measure in each region. In Flanders we measure transitions to short-term jobs by the cumulative fraction of individuals that has been working under a temporary agency contract for 10 days or more in at least one of the preceding 6,12 or 18 months. Note that these jobs are registered only as from 2012. In Wallonia we measure the cumulative share of individuals transiting within the preceding 6,12 or 18 months to a job that lasts at least one day. ${ }^{7}$

Our second main outcome is the employment rate measured at the end of the $6^{\text {th }}, 12^{\text {th }}$ and $18^{\text {th }}$ month after registration. This outcome is defined as the share of unemployed job seekers who are in employment at these moments. While the job finding rate allows us to evaluate whether or not the 2015 reform has affected the transition to any job, the employment probability is used to test whether the reform contributed to employment stability. Employment is measured as in a cross section on the last day of the month. This means that longer employment spells are more likely observed than shorter ones.

We measure the job finding and employment rates in the middle of and at the end of the waiting period ( 6 and 12 months after registration), and 6 months after its end, i.e. 18 months after registration. At this moment the unemployed graduates who were not affected by the reform could receive the benefit payments, while the affected group could no longer do so. Comparing employment and job finding rates of treated and non-treated labor market entrants measured 6 or 12 months after registration allows us to test whether these youths anticipate the future loss of entitlement to unemployment benefits. Comparing these outcomes after 18 months allows us to test whether, in addition to the anticipation effect, the actual loss of eligibility to unemployment benefits further affects employment.

\footnotetext{
${ }^{6}$ See Cockx et al. (2019) for an evaluation of the policy reform affecting high school dropouts.

7 In Wallonia, this second definition of job finding differs from the first one in that the latter includes self-employment and some cross-border work, while the second one does not. This explains that, although much less restrictive in the definition of the employment duration, the second job finding rate may be below the first one.
} 
We have measurements of employment outcomes of job seekers registering at the PES in 2011-2013 (pre-treatment period) and 2014 (post-treatment period). Since the decision to register as a job seeker might be influenced by the policy reform, we limit the post-reform period to job seekers who registered in 2014, before the announcement of the reform. Individuals registering as a job seeker in 2014 can be affected by the reform only as from January 2015. The reform can therefore not influence the employment and job finding rates within 6 months after registration of the group who registered as unemployed job seeker in 2014 before July. Consequently, to study the impact of the policy change, we focus on the large subsample of university graduates who registered during the second half of the year. More precisely, given data availability, we focus on those who registered at the PES between June and October, which includes July and September, months in which most university students graduate.

\section{Empirical strategy}

To estimate the causal impact of the policy change, we make use of the difference-in-differences approach and compare employment outcomes in the treatment group before and after the policy reform with employment outcomes at the same moments in the control group.

Data limitations prevent us from delineating treatment and control groups perfectly. The treatment group consist of individuals who are in the waiting period for the activation allowance at the end of 2014, but who, as a consequence of the reform, unexpectedly fail to meet the new eligibility criteria. By contrast, in the data we measure the labor outcomes of all individuals who registered in 2014 as unemployed job seeker at the PES: We cannot identify the sub-population for which the waiting period is ongoing at the end of 2014 because some job seekers could already have found a stable job before 2015. Other job seekers could be back in education or out of the labor force at this moment. Consequently, not all job seekers in the treatment group are effectively treated. Furthermore, for a subgroup of the considered population the waiting period may already have expired before the end of 2014, because we cannot exclude that some individuals, who registered at the PES for the first time in 2014, started this period already in 2013. This concerns young people who immediately started working upon labor market entry - which counts for the waiting period. Focusing on job seekers who registered at the PES between June and October reduces the relative importance of this group. Finally, the minority who collects welfare benefits during this one-year period is not affected by the loss of entitlement to the activation allowance. Since we cannot exclude non-compliance for these reasons, the identified treatment effects must be interpreted as intention-to-treat effects.

Since our sample consists of job seekers registering at the PES between June and October, in principle the period that job seekers were exposed to the policy change varies between zero and four months when considering employment outcomes measured 6 months after registration. ${ }^{8}$ However, because there is a rule that for youth graduating in June or July, the waiting period cannot begin before August 1 , the period of exposure to the policy ranges for the majority of the individuals between two and four months. Among the group of youths who registered for the first time as a job seeker between June and October 2014 in Wallonia, 41\% did so in September (Forem, 2015). They were thus treated during a period of three months before our first outcome was measured.

We estimate the policy impact within a linear probability model using ordinary least squares and Huber-White heteroskedastic robust standard errors. This is done by expanding the grouped data to the individual level using the number of individuals within each group (Angrist and Pischke, 2013, p.

\footnotetext{
${ }^{8}$ For someone who registers at the PES in October 2014, this outcome is measured at the end of April 2015, i.e. 6 full months after registration and 4 months after the reform was announced on January 12015.
} 
40). ${ }^{9}$ The difference-in-differences approach implies that the treatment effect can be estimated using the following specification for the linear probability model:

$$
Y_{i t}=\alpha+\beta D_{i}+\gamma_{t} T_{t}+\delta D_{i} T_{2014}+\epsilon_{i t}
$$

for $t \in\{2011, \ldots, 2014\}$, and where $Y_{i t}$ is a dummy equal to one if individual $i$, who registered at the PES during year $t$ finds a (temp) job within 6,12 or 18 months after registration (alternatively, is employed at the end of the 6th, 12th or 18th month). $D_{i}$ is an indicator equal to one if the job seeker is affected by the policy change. $T_{2014}$ is an indicator equal to one if the individual registered at the PES in year 2014. $\delta$ is the difference-in-differences estimator of the impact of the reform on the outcome.

This model controls for any potential time-constant difference between the employment outcomes of job seekers in the control group and the treatment group, captured by $\beta$, and time effects common to both, captured by $\gamma_{t}$. Nonetheless, it rules out additional time effects that differ between the treated and control group in the absence of the reform. In particular, this model relies on the assumption that both groups would have followed a common trend in their employment outcomes if the reform had not taken place. Under this identifying assumption, the parameter $\delta$ captures any deviation from this common trend induced by the reform, that is, its causal effect. To formally assess the validity of our common trends assumption, we test whether the employment rate and job finding rate of the treated and control groups deviated from a common trend during the pre-treatment period 2011-2013. Therefore, we estimate a similar regression with interaction effects between the treatment group and year dummies in the pre-reform period. The parallel trends assumption is rejected if these interaction effects are jointly significantly different from zero.

\section{Results}

Figure 2 compares the job finding rates (panels $A$ and $B$ ) and the employment rate (panel C) of 23-and 24-year-old job seekers who registered at the PES with a master's degree between June and October. The outcomes are measured 6 months after the first registration as a job seeker. Table A1 in Appendix summarizes these outcomes at all three time horizons before and after the reform.

In Figure 2, the year of registration is on the horizontal axis and outcomes are shown before (20112013, and 2012-2013 for employment in temp job in Flanders) and after (2014) the policy reform. The thick solid line shows the observed job finding and employment rates for 24-year-old job seekers (treatment group). The thin solid line presents the counterfactual outcome of the treatment group in the absence of the policy reform. The counterfactual outcome is predicted by a difference-indifferences model with interaction effects between the treatment group and time dummies for the pre- and post-reform periods. This outcome is obtained by setting these interaction effects to zero. The corresponding $95 \%$ confidence interval is computed from the standard errors of the interaction effects between time dummies and the treatment group. The counterfactual outcome is shifted to the level of the observed outcome of the treated in the year before the policy reform. By construction, the confidence interval is zero for this year (the reference one).

\footnotetext{
${ }^{9}$ Note that this expansion to the individual level is only possible because of the binary nature of our outcome variable. A referee raised that we should have ideally clustered standard errors by month of registration as to take seasonal effects into account. Unfortunately, there are no data available at this level of disaggregation. This means that the standard errors are presumably underestimated.
} 


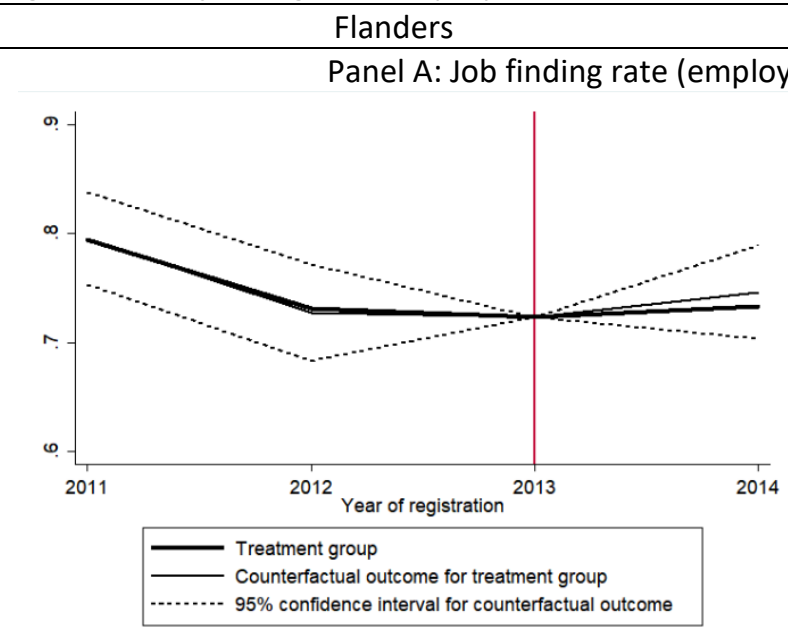

Wallonia

Flanders

the month)

Panel B: Job finding rate (alternative outcomes)

Employed in a temp job
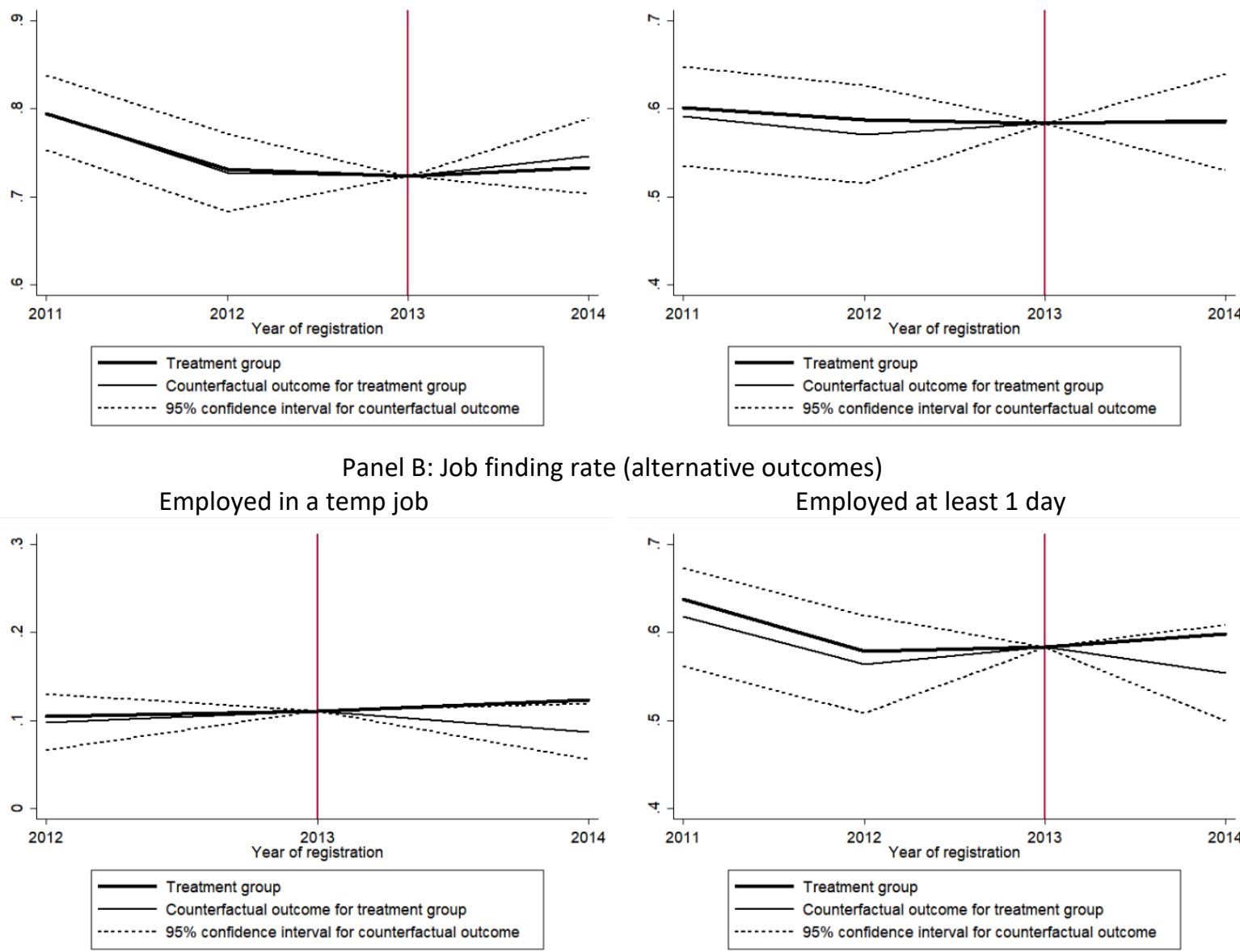

Employed at least 1 day

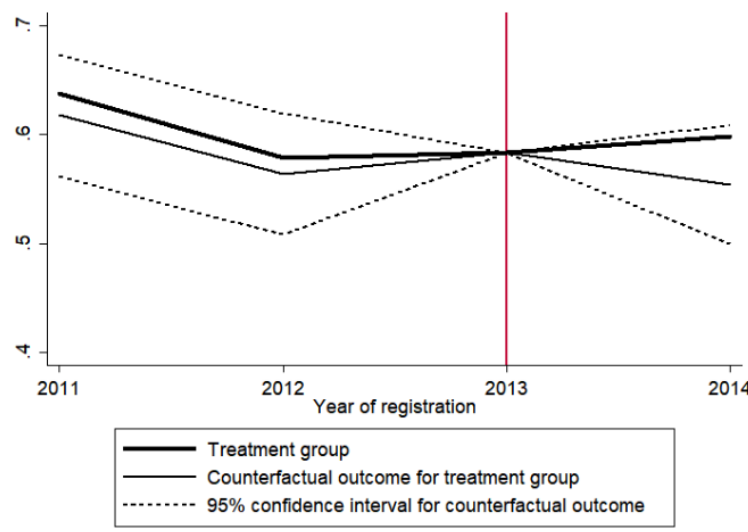

Panel C: Employment rate
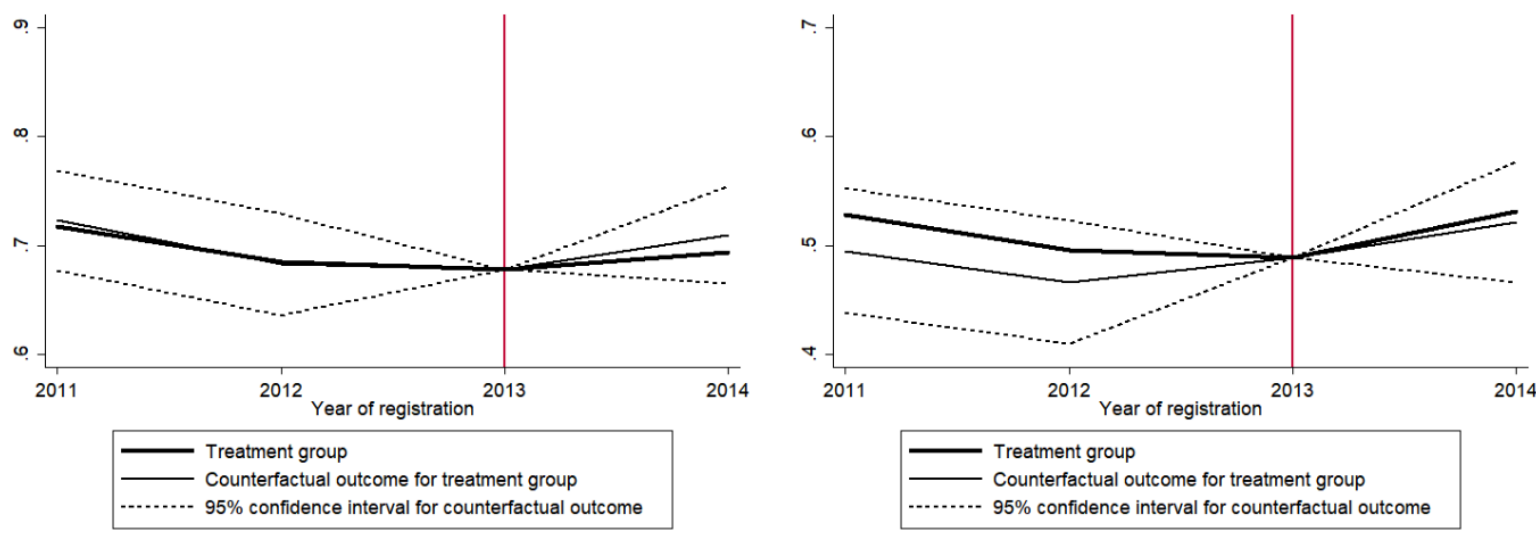

Notes: Treatment group $=24$-year-old job seekers. Control group $=23$-year-old job seekers. Outcomes are measured 6 months after registration at the PES for job seekers who register between June and October after having obtained a master's degree. The vertical line is drawn at the last period before the reform. The thick solid line shows the observed outcome of the treatment group. The fine solid line shows the counterfactual outcome of the treatment group in absence of the treatment. The thin dotted lines are the $95 \%$ confidence interval for the counterfactual path.

The first panel shows the job finding rate when employment is measured only on the last day of the month. Before the policy reform approximately $75 \%$ (59\%) of job seekers in the treatment group in Flanders (Wallonia) have transited at least once to a job. Comparing the observed outcomes of the 
treated (thick solid line) with their counterfactual outcome in absence of the reform (thin solid line) provides a first assessment of the parallel trends assumption. From both graphs, we see that the observed outcome of the treatment group remains within the $95 \%$ confidence interval of their counterfactual outcome of the treatment group before the policy reform. This suggests that the parallel trends assumption is not rejected for both regions. In 2014, the year of registration where job seekers are affected by the policy reform, the observed outcome for the job finding rate is also similar to the counterfactual outcome of the treated and remains within the $95 \%$ confidence interval in both Flanders and Wallonia.

Panel B shows our alternative measures for the job finding rate when employment is also measured if the individual did not work on the last day of the month. The first figure shows the job finding rate limited to temp jobs in Flanders. This outcome is observed only as from 2012. Before the policy reform, $11 \%$ of job seekers in Flanders were at least once employed by a temporary agency within 6 months after registration. In 2014, the observed outcome of the treatment group just exceeds the upper bound of the $95 \%$ confidence interval. The next figure in panel $B$ shows the job finding rate to jobs lasting at least one day in Wallonia. In contrast to the job finding rate in panel $A$, this outcome is more likely to capture very short-term employment. Although the observed outcome of the treated remains within the $95 \%$ confidence interval of the counterfactual outcome, this outcome approaches the upper bound of the confidence interval, suggesting a positive effect of the policy reform on this measure of the job finding rate.

Panel $C$ shows the employment rate or the fraction of job seekers who is employed 6 months after registration. Before the policy reform $69 \%$ (50\%) of job seekers in the treatment group in Flanders (Wallonia) is employed 6 months after registration. As the observed employment rate of the treated remains within the $95 \%$ confidence interval both before and after the policy reform, these figures suggest that losing future eligibility to the activation allowance did not affect employment at the end of the sixth month.

Figure A1 in the appendix is the analog to Figure 2 where all outcomes are measured 12 months after registration. Job finding and employment rates measured after 12 months are higher than after 6 months, but the trends before and after the reform are similar. In Flanders (Wallonia), 17\% (34\%) of young labor market entrants in 2014 in the control group is not employed at the end of the $12^{\text {th }}$ month, i.e. the scheduled end date of the waiting period. These figures give an upper bound of the benefit take-up rates among this population because we cannot exclude that some of these individuals were not actively looking for a job anymore. Finally, Figure A2 in Appendix shows the corresponding graphical analysis for the job finding and employment rates measured after 18 months. This allows us to test whether the actual loss of entitlement to UI affects employment in addition to the anticipation effect. The trends are similar as for the job finding and employment rate measured respectively 6 and 12 months after registration. While there is no effect of the reform on the employment rate (panel C) and the job finding rate limited to jobs measured on the last day of the month (panel A), scrapping entitlement to UI has raised the job finding rate to temporary jobs (panel B).

Table 4 presents the output of the difference-in-differences estimation for the job finding and employment rates within respectively 6,12 and 18 months. We present only the coefficients of the treatment effects and the counterfactual outcomes of the treated in absence of the policy reform as predicted by our model. To test for parallel trends, we estimate placebo regressions for the differencein-differences model on the pre-reform period and include interaction effects between the treatment group and time dummies. The $p$-value of the F-test that the interaction effects are jointly insignificantly different from zero is reported in the Table. Based on these $p$-values, we can conclude that the parallel trends assumption is never rejected at the $5 \%$ and even $10 \%$ level. 
The results in panel $A$ of Table 4 suggest that the reform did not increase the job finding rate if jobs are measured on the last day of the month only. In contrast, panel B shows that losing future entitlement to $\mathrm{UI}$ significantly raised the fraction of youths who had a temporary job experience in Flanders. The fraction of youths who had at least one temp job has increased by 3.3 percentage points within 6 months after registration. In absence of the reform, 9.0\% of job seekers would have found a temp job. This fraction increased to $12.3 \%$ because of the policy reform, a relative effect of $36.7 \%$. The effects are similar when measured after 12 and 18 months. In Wallonia, we estimate a non-negligible positive effect for the job finding rate to jobs lasting at least one day after 6,12 and 18 months. However, only the effect measured within 12 months is significant at the $10 \%$ level. The fact that treatment effects are similar when measured at the three different time horizons for the cumulative job finding rates implies that although job finding increased immediately after the announcement of the policy reform (outcomes measured after 6 months), there is no clear additional effect on job finding after the sixth month in the waiting period, or if there is, it cannot be measured with the given precision of our estimates.

Table 4: Treatment effects on job finding and employment rates (difference-in-differences)

\begin{tabular}{|c|c|c|c|c|c|c|}
\hline & \multicolumn{3}{|c|}{ Flanders } & \multicolumn{3}{|c|}{ Wallonia } \\
\hline & 6 months & 12 months & 18 months & 6 months & 12 months & 18 months \\
\hline & \multicolumn{6}{|c|}{ Panel A: Job finding rate (employed on the last day of the month) } \\
\hline \multirow[t]{2}{*}{ Treatment effect } & -0.013 & -0.001 & -0.001 & -0.007 & 0.006 & 0.012 \\
\hline & $(0.018)$ & $(0.013)$ & $(0.010)$ & $(0.023)$ & $(0.020)$ & $(0.017)$ \\
\hline Counterfactual probability & 0.747 & 0.879 & 0.928 & 0.594 & 0.733 & 0.820 \\
\hline Parallel trends: $p$-value & 0.976 & 0.681 & 0.395 & 0.832 & 0.995 & 0.515 \\
\hline \multirow[t]{3}{*}{ Observations } & 12634 & 12634 & 12634 & 9728 & 9728 & 9728 \\
\hline & \multicolumn{6}{|c|}{ Panel B: Job finding rate (alternative outcomes) } \\
\hline & \multicolumn{3}{|c|}{ Employed in a temp job } & \multicolumn{3}{|c|}{ Employed at least 1 day } \\
\hline \multirow[t]{2}{*}{ Treatment effect } & $0.033^{* *}$ & $0.038 * *$ & $0.037^{* *}$ & 0.032 & $0.037^{*}$ & 0.021 \\
\hline & $(0.014)$ & $(0.015)$ & $(0.016)$ & $(0.023)$ & $(0.020)$ & $(0.019)$ \\
\hline Counterfactual probability & 0.090 & 0.121 & 0.137 & 0.566 & 0.700 & 0.776 \\
\hline Parallel trends: $p$-value & 0.699 & 0.893 & 0.954 & 0.765 & 0.661 & 0.998 \\
\hline \multirow[t]{2}{*}{ Observations } & 9639 & 9639 & 9639 & 9728 & 9728 & 9728 \\
\hline & \multicolumn{6}{|c|}{ Panel C: Employment rate } \\
\hline \multirow[t]{2}{*}{ Treatment effect } & -0.015 & 0.002 & -0.009 & -0.010 & 0.004 & 0.004 \\
\hline & (0.019) & $(0.016)$ & $(0.013)$ & $(0.023)$ & $(0.022)$ & $(0.022)$ \\
\hline Counterfactual probability & 0.709 & 0.814 & 0.881 & 0.542 & 0.619 & 0.596 \\
\hline Parallel trends: $p$-value & 0.952 & 0.671 & 0.407 & 0.458 & 0.821 & 0.848 \\
\hline Observations & 12634 & 12634 & 12634 & 9728 & 9728 & 9728 \\
\hline
\end{tabular}

Notes: Treatment group $=24$-year-old job seekers. Control group $=23$-year-old job seekers. Age is measured at the moment of registration as a job seeker. Control period $=2011-2013$ (2012-2013 for employment in temp jobs in Flanders), treatment period $=2014$. Outcomes are measured for job seekers who register between June and October after having obtained a master's degree. The counterfactual outcome is the predicted outcome for the treated in absence of the treatment in the post-reform period. To test for parallel trends, we estimate similar regressions with interaction effects between the treatment groups and year dummies. The parallel trends assumption is rejected if these interaction effects are jointly significantly different from zero in the pre-reform period. The $p$-value of the test is reported. Robust standard errors in parentheses. * $p<0.1, * * p<0.05, * * * p<0.01$.

As since January 2012, the activation allowance is time limited, we restrict the analysis to the job seekers registering as from 2012 in a robustness check. The results displayed in Table A2 in the appendix confirm our previous results. Moreover, the job finding rate to jobs lasting at least one day measured after 12 months in Wallonia now becomes significant at the $5 \%$ level. 
How can we interpret these findings? Job search theory predicts that abolishing the entitlement to UI should enhance job search effort and reduce selectivity in the job acceptance behavior (Mortensen, 1977 and van den Berg 1990). To the extent that the unemployed are forward looking, these effects should already be observed prior to the end of the waiting period, from the moment the unemployed are informed about the reform. Our results are qualitatively in line with this prediction. The prospect of losing entitlement has a clear positive effect on the fraction of graduate job seekers getting temp jobs in Flanders. This enhanced transition to temp jobs occurs well before the end of the waiting period, i.e. already 6 months after registration in unemployment. Effects of a similar order of magnitude are estimated in Wallonia on cumulative transitions to jobs lasting at least one day, although they are not as precisely estimated. When we consider discrete time job finding rates and employment probabilities at the end of the month, the effects are instead small and statistically not significantly different from zero in both regions. This suggests that the reform has only accelerated transitions to short-term jobs and this only for a small fraction of the targeted population.

A plausible explanation of these findings is that non-stationary forces driven by dynamic selection or negative duration dependence are at work (Kolsrud et al., 2018). The first force causes the recent graduates who are most sensitive to financial incentives and employable in high quality jobs to leave unemployment before the moment at which the prospect of losing entitlement to UI could start to impact their behavior. This interpretation assumes that the population of young graduates is heterogeneous and that those who end up in long-term unemployment either do not react to financial incentives or, if they do, they have only opportunities for very short-term jobs. The second force applies also for homogeneous populations. In this case the sensitivity to monetary incentives and the quality of job opportunities decline with unemployment duration. Whichever explanation holds, they are both consistent with our findings of weak impact on job finding and enhanced transitions to shortlived jobs. Moreover, these mechanisms can also explain why there is a declining profile in the treatment effect in Panel B of Table 4: as compared to the effect measured at 6 months, there is a weak additional effect at 12 months and no supplementary one when the loss of eligibility becomes real. It is possible that as from these moments onwards all individuals who are sensitive to financial incentives have already left unemployment or that this sensitivity has further declined close to a zero level.

Significant effects being exclusively measured for the transitions to short-term jobs suggest that these behavioral reactions come from liquidity constrained individuals who become less selective in their job acceptance behavior. If so, this would imply that the reform has induced an efficiency cost in terms of foregoing consumption smoothing gains (Chetty, 2008; Card et al. 2007). However, in any event the share of these liquidity constrained individuals is small and it is not clear to what extent a similar efficiency cost also applies for the majority for whom we do not observe such reaction. For instance, it is possible that parents absorb the income loss that the reform imposes on their children. This could also explain the absence of a reaction for this group.

Our finding that there is no ex-post effect of actually losing benefit eligibility is in line with Bargain and Doorley (2011). They study in a regression discontinuity design the impact on the employment rate of the eligibility for a means-tested minimum income as from age 25 in France for childless single men. They find modest employment responses for high school dropouts and zero effects for higher educated. However, the latter result is not driven by a lower sensitivity to financial incentives but arguably because graduate men have higher earnings potential and, hence, are less affected by the eligibility for the means-tested benefit. In contrast, von Buxhoeveden (2019) shows for Sweden that the employment hazard significantly decreases once high school leavers become entitled to UI after a waiting period which partly depends on age. Also, Bolhaar et al. (2019) find that imposing a job search period before the entitlement to means-tested welfare benefits in the Netherlands substantially increases the likelihood to find a full-time job and reduces the benefits take-up rate. A possible explanation for the relatively important effects in the last two studies is that the first study includes 
relatively short waiting periods and the latter an introduction of such a period. In both cases, incentives kick in before individuals highly sensitive to monetary incentives have left unemployment. However, the fact that Bolhaar et al. (2019) consider only individuals with very limited financial resources could also explain why they find larger effects than in our paper.

Finally, our results also imply that temp jobs appear not be 'stepping stones' to more stable jobs. This is in line with the study of Givord and Wilner (2015). They conclude (p. 787) that "although fixed-term contracts may provide a 'stepping-stone' to permanent positions, temporary agency work is hardly better than unemployment in this regard". Autor and Houseman (2010) and, more recently, van der Klaauw and Ziegler (2019) also find that temp jobs do not serve as stepping stones towards regular employment or better paying jobs. Our findings are also consistent with those of Cockx and Van Belle (2019) who found that extending the waiting period of the activation allowance from 9 to 12 months for graduates of a master's degree did not significantly affect the discrete time transition to employment measured in a very similar way as in this study, while it appears to have reduced the number of working days and earnings.

\section{Concluding Remarks}

This paper has evaluated the impact on the transition to work of a policy reform that restricted the access of young labor market entrants to a particular unemployment benefit (UB) scheme. Under certain conditions these youths could claim unemployment benefits after a waiting period of one year. As of 2015, the Belgian government unexpectedly scrapped entitlement to these benefits for youths who start the waiting period at the age of 24 or older. The reform implied a change from an inclining to a flat rate (zero) benefit profile for individuals leaving education at these ages.

Based on grouped data of university graduates aged 23 and 24 at the start of unemployment we used a difference-in-differences approach to find an answer to our research question. Our main finding is that scrapping the entitlement to UB of young labor market entrants only stimulated the transitions to very short-term jobs. The transitions to longer-lasting jobs remained unaffected. We argued that these findings are in particular consistent with those of Kolsrud et al. (2018) for the regular UI scheme in Sweden, namely that the behavioral reaction to changes in the benefit generosity is smaller for longterm than for short-term unemployed. The zero-benefit level during the one-year waiting period likely induced the youths most sensitive to monetary incentives to leave unemployment prior to the moment that the anticipation of the loss of the UI entitlement could start to bite.

The observed increase in the fraction of treated youths who found a short-lived job could be the result of liquidity constrained youths who became less selective in their job acceptance behavior. For them, scrapping entitlement to UI may have induced an efficiency cost in terms of forgoing consumption smoothing gains (Chetty, 2008). However, only 3 to $4 \%$ of all university graduates who were intendedly treated youths were incentivized to accept a short-term work experience. This suggests the share of liquidity constrained individuals is small among graduates. Moreover, an alternative reason of why we do not find any behavioral effects for a large share of the population is that parents might have absorbed the income loss that the reform has generated for their children. Therefore, our findings do not necessarily imply that restoring the inclining $\mathrm{UI}$ benefit profile would be a policy to recommend, because it might also provide insurance to a group that is not at all liquidity constrained. Unfortunately, our data do not allow to identify to what extent the latter hypothesis holds or not.

There are two further limitations of our study. First the results should be interpreted as intent-to-treat estimates and, hence, as lower bounds of the actual treatment effects. This is because we cannot identify those who were still at risk of losing their entitlement to UB at the moment the reform was 
announced. Second we only had access to grouped data and to a limited set of outcome variables. Consequently, we could neither analyze treatment heterogeneity, nor investigate to what extent the reform pushed these youths into poverty or affected other dimensions of job quality than duration. An avenue of future research is therefore to address these limitations by collecting new data.

\section{References}

A-Kasser (2019), Apply for membership of an unemployment fund - special rule for new graduates, https://www.akasser.dk/graduates, accessed (12/03/2019)

Angrist, J. and Pischke, J. (2013), Mostly harmless econometrics: an empiricists companion

Autor, D. and Houseman, S. (2010), Do temporary-help jobs improve labor market outcomes for lowskilled workers? Evidence from "Work First", American Economic Journal: Applied Economics, 2(3), 96128

Bargain, O. and Doorley, K. (2011), Caught in the trap? Welfare's disincentive and the labor supply of single men, Journal of Public Economics, 9-10, 1096-1110

Bolhaar, J., Ketel, N. and van der Klaauw, B. (2019), Job search periods for welfare applicants: Evidence from a randomized experiment, American Economic Journal: Applied Economics, 11(1), 92-125

Caliendo, M., Tatsiramos, K., and Uhlendorff, A. (2013), Benefit duration, unemployment duration and jobmatch quality: A regression discontinuity approach, Journal of Applied Econometrics, 28(4), 604627

Card, D., Chetty, R., and Weber, A. (2007), Cash-on-hand and competing models of intertemporal behavior: New evidence from the labor market, The Quarterly Journal of Economics, 122(4), 1511 1560

Centeno, M. and Novo, A. (2009), Reemployment wages and UI liquidity effect: A regression discontinuity approach, Portuguese Economic Journal, 8(1), 45-52

Chetty, R. (2008), Moral hazard versus liquidity and optimal unemployment insurance, Journal of Political Economy, 116(2), 173-234

Cockx, B., Dejemeppe, M., Launov, A. and Van der Linden, B. (2018), Imperfect Monitoring of Job Search: Structural Estimation and Policy Design, Journal of Labor Economics, 36 (1): 75-120

Cockx, B., Declercq, K., Dejemeppe, M., Inga, L. and Van der Linden, B. (2019), Scrapping the entitlement to unemployment benefits for young labor market entrants: An effective way to get them to work?, NBB Working Paper Research, No 379

Cockx, B. and Van Belle, E. (2019), Waiting longer before claiming, and activating youth: no point?, International Journal of Manpower, 40(4), 658-687

de Groot, N. and van der Klaauw, B. (2019), The effects of reducing the entitlement period to unemployment insurance benefits, Labour Economics, 57, 195-208 
Forem (2015), L'insertion au travail des jeunes demandeurs d'emploi wallons sortis de l'enseignement en 2014, Marché de l'emploi : Analyse, August 2015

Givord, P. and Wilner, L. (2015), When does the stepping-stone work? Fixed-term contracts versus temporary agency work in changing economic conditions, Journal of Applied Econometrics, 30, 787805

IDD (2012), Le point sur les jeunes qui bénéficient d'un revenu d'intégration "étudiant", Institut pour un Développement Durable, Octobre 2012

Kolsrud, J., Landais, C., Nilsson, P. and Spinnewijn, J. (2018), The optimal timing of unemployment benefits: Theory and evidence from Sweden, American Economic Review, 108 (4), 985-1033

Kroft, K., Lange, F. and M. J. Notowidigdo (2013), Duration dependence and labor market conditions: evidence from a field experiment, Quarterly Journal of Economics, 128(3), 1123-1167

Lalive, R. (2007), Unemployment benefits, unemployment duration, and post-unemployment jobs: A regression discontinuity approach, American Economic Review, 97(2), 108-112

Langenbucher, K. (2015), How demanding are eligibility criteria for unemployment benefits, quantitative indicators for OECD and EU countries, OECD Social, Employment and Migration Working Papers No. 166, OECD Publishing, Paris.

Le Barbanchon, T. (2016), The effect of the potential duration of unemployment benefits on unemployment exits to work and match quality in France, Labour Economics, 42, 16-29

Lindner, A. and Reizer, B. (2019), Frontloading and the unemployment benefit: An empirical assessment, American Economic Journal: Applied Economics, forthcoming

Luxembourg Employment Agency (2020), https://adem.public.lu/en/demandeursdemploi/demander-indemnites-chomage/residents/jeunes-sortant-de-lecole.html, accessed $(10 / 02 / 2020)$

Michelacci, C. and Ruffo, H. (2015), Optimal life cycle unemployment insurance, American Economic Review, 105(2), 816-859

Mortensen, D. (1977), Unemployment insurance and job search decisions, Industrial and Labor Relations Review, 30(4), 505-517

Mueller, A., Spinnewijn J. and Topa G. (2019), Job seekers' perceptions and employment prospects: Heterogeneity, duration dependence and bias, CEPR Discussion Paper No. DP13774

Nekoei, A. and Weber, A. (2015), Recall expectations and duration dependence, American Economic Review, 105(5), 142-46

Nekoei, A and Weber, A (2017), Does Extending Unemployment Benefits Improve Job Quality?, American Economic Review, 107(2), 527-561

ONEM (2013), L'ONEM en 2013, volume 2

ONEM (2014), L'ONEM en 2014, volume 2 
Schmieder, J. and von Wachter, T. (2016). The effects of unemployment insurance: New evidence and interpretation. Annual Review of Economics 8, 547-581.

Schmieder, J., von Wachter, T. and Bender, S. (2016), The effect of unemployment benefits and nonemployment durations on wages, American Economic Review, 106(3), 739-777

Tatsiramos, K. (2009), Unemployment insurance in Europe: Unemployment duration and subsequent employment stability, Journal of the European Economic Association, 7(6), 1225-1260

Tatsiramos, K. and Van Ours, J. (2014), Labor market effects of unemployment insurance design, Journal of Economic Surveys, 28 (2), 284-311

Van Den Berg, G. (1990), Nonstationarity in job search theory, The Review of Economic Studies, 57(2), 255-277

van der Klaauw, B. and Ziegler, L. (2019), A field experiment on labor market speeddates for unemployed workers, IZA Discussion Papers 12140

van Ours, J. and Vodopivec, M. (2006), How shortening the potential duration of unemployment benefits affects the duration of unemployment: Evidence from a natural experiment, Journal of Labor Economics, 24(2), 351-378

von Buxhoeveden (2019), Unemployment insurance and youth labor market entry, IFAU Working paper 2019:12 


\section{Appendix}

Table A1: Job finding and employment rates

\begin{tabular}{|c|c|c|c|c|}
\hline & \multicolumn{2}{|c|}{ Pre-reform period } & \multicolumn{2}{|c|}{ Post-reform period } \\
\hline & Age 23 & Age 24 & Age 23 & Age 24 \\
\hline \multicolumn{5}{|c|}{ Flanders } \\
\hline \multicolumn{5}{|c|}{ Job finding rate: Employed on the last day of the month } \\
\hline after 6 months & 0.77 & 0.75 & 0.77 & 0.73 \\
\hline after 12 months & 0.90 & 0.88 & 0.90 & 0.88 \\
\hline after 18 months & 0.93 & 0.92 & 0.94 & 0.93 \\
\hline No. of individuals & 5541 & 3748 & 1979 & 1366 \\
\hline \multicolumn{5}{|c|}{ Job finding rate: Alternative outcomes (Employed in a temp job) } \\
\hline after 6 months & 0.12 & 0.11 & 0.10 & 0.12 \\
\hline after 12 months & 0.15 & 0.14 & 0.13 & 0.16 \\
\hline after 18 months & 0.16 & 0.16 & 0.14 & 0.17 \\
\hline No. of individuals & 3723 & 2571 & 1979 & 1366 \\
\hline \multicolumn{5}{|l|}{ Employment rate } \\
\hline after 6 months & 0.72 & 0.69 & 0.73 & 0.69 \\
\hline after 12 months & 0.80 & 0.78 & 0.83 & 0.82 \\
\hline after 18 months & 0.87 & 0.85 & 0.90 & 0.87 \\
\hline No. of individuals & 5541 & 3748 & 1979 & 1366 \\
\hline \multicolumn{5}{|c|}{ Wallonia } \\
\hline \multicolumn{5}{|c|}{ Job finding rate: Employed on the last day of the month } \\
\hline after 6 months & 0.60 & 0.59 & 0.60 & 0.59 \\
\hline after 12 months & 0.76 & 0.75 & 0.74 & 0.74 \\
\hline after 18 months & 0.87 & 0.86 & 0.83 & 0.83 \\
\hline No. of individuals & 3898 & 3253 & 1366 & 1211 \\
\hline \multicolumn{5}{|c|}{ Job finding rate: Alternative outcomes (Employed at least 1 day) } \\
\hline after 6 months & 0.62 & 0.60 & 0.59 & 0.60 \\
\hline after 12 months & 0.74 & 0.72 & 0.72 & 0.74 \\
\hline after 18 months & 0.79 & 0.77 & 0.79 & 0.80 \\
\hline No. of individuals & 3898 & 3253 & 1366 & 1211 \\
\hline \multicolumn{5}{|l|}{ Employment rate } \\
\hline after 6 months & 0.53 & 0.50 & 0.57 & 0.53 \\
\hline after 12 months & 0.63 & 0.59 & 0.66 & 0.62 \\
\hline after 18 months & 0.72 & 0.70 & 0.62 & 0.60 \\
\hline No. of individuals & 3898 & 3253 & 1366 & 1211 \\
\hline
\end{tabular}

Notes: Average outcomes for 23- and 24-year-old job seekers with a master's degree, registering between June and October. Pre-reform period $=2011-2013$ (2012-2013 for employment in temp jobs in Flanders), post-reform period $=2014$. Outcomes for the job finding rate to temp jobs in Flanders are limited to the period 2012-2014. Age is measured at the moment of registration as a job seeker. Individuals registering at the age of 24 were not eligible anymore for the activation allowance after the reform. Individuals registering at the age of 23 can still claim the activation allowance. The employment and job finding rates are measured within 6,12 and 18 months after the month of registration. For both regions, the first and third outcome includes self-employment, while this second one does not. 
Figure A1: Job finding and employment rates (12 months after registration)

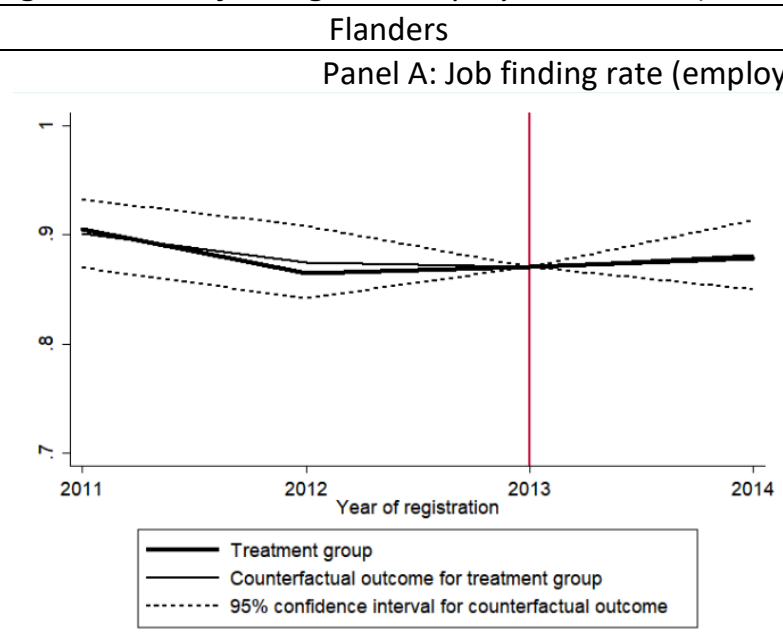

Wallonia

Flanders

the month)

Panel B: Job finding rate (alternative outcomes)

Employed in a temp job

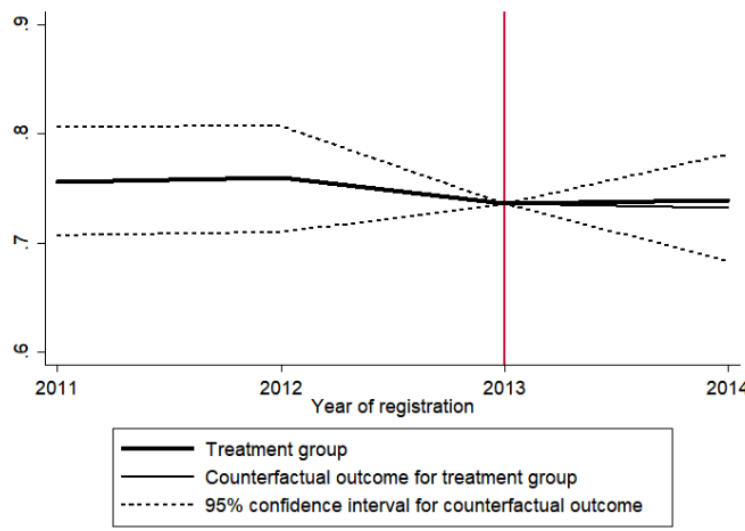

Employed at least 1 day
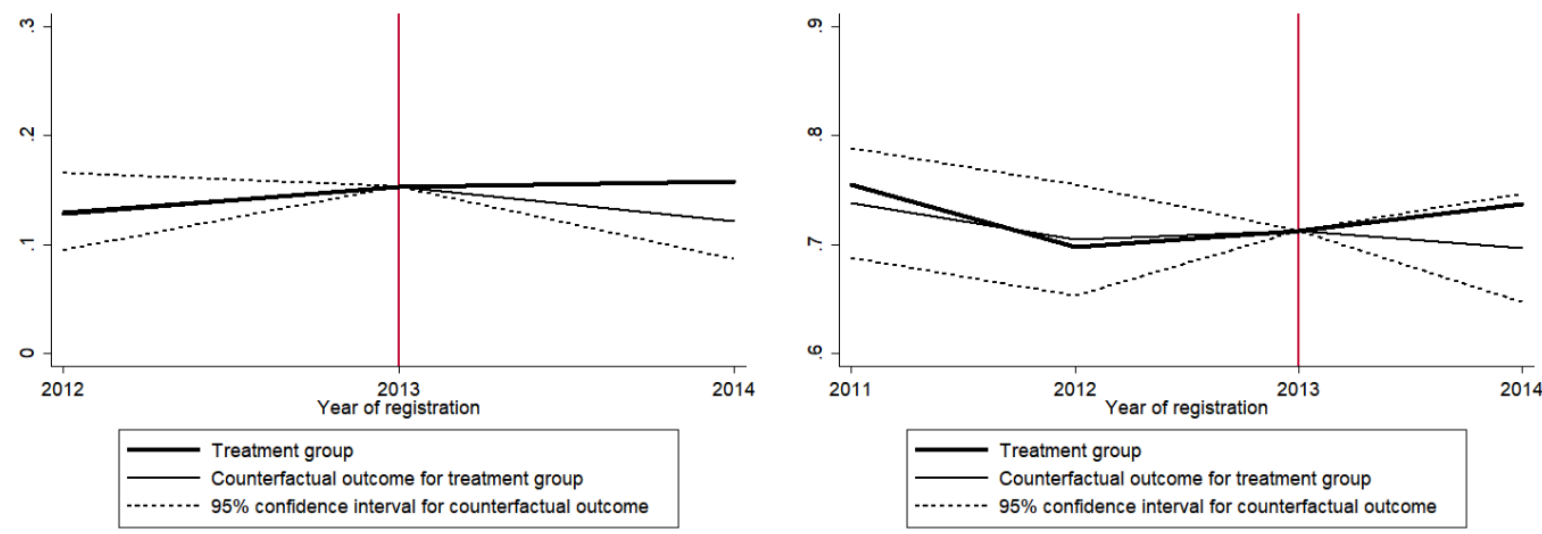

Panel C: Employment rate
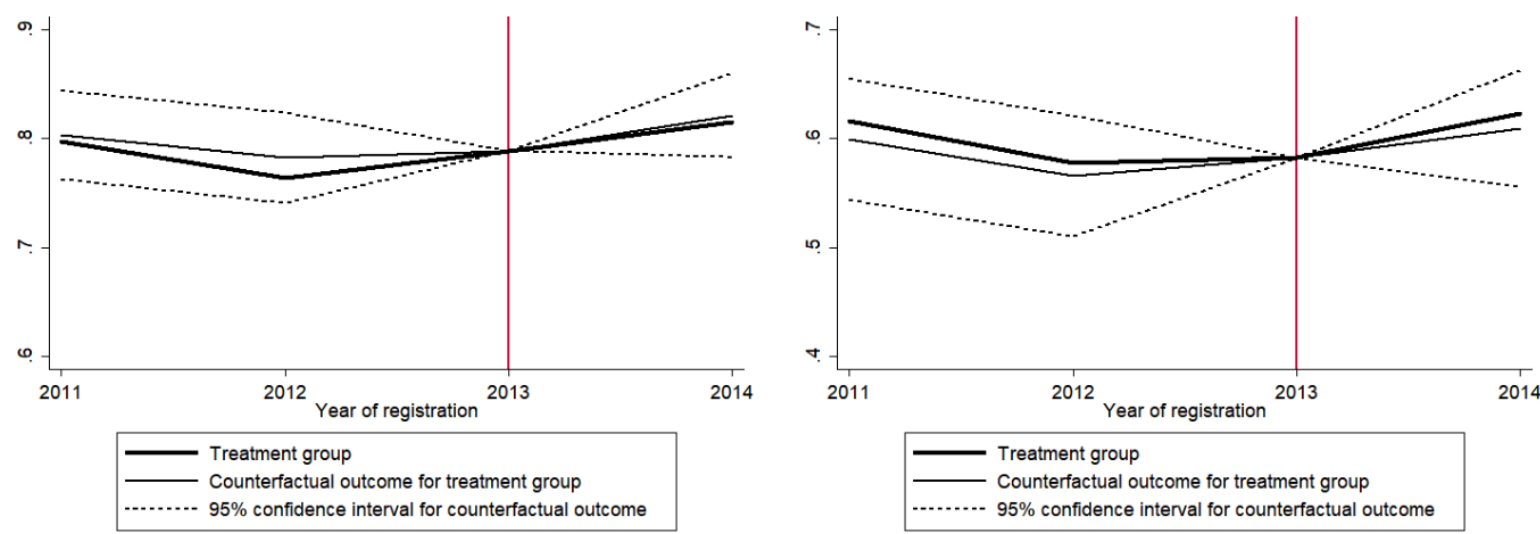

Notes: Treatment group $=24$-year-old job seekers. Control group $=23$-year-old job seekers. Outcomes are measured 12 months after registration at the PES for job seekers who register between June and October after having obtained a master's degree. The vertical line is drawn at the last period before the reform. The thick solid line shows the observed outcome of the treatment group. The fine solid line shows the counterfactual outcome of the treatment group in absence of the treatment. The thin dotted lines are the $95 \%$ confidence interval for the counterfactual path. 
Figure A2: Job finding and employment rates (18 months after registration)

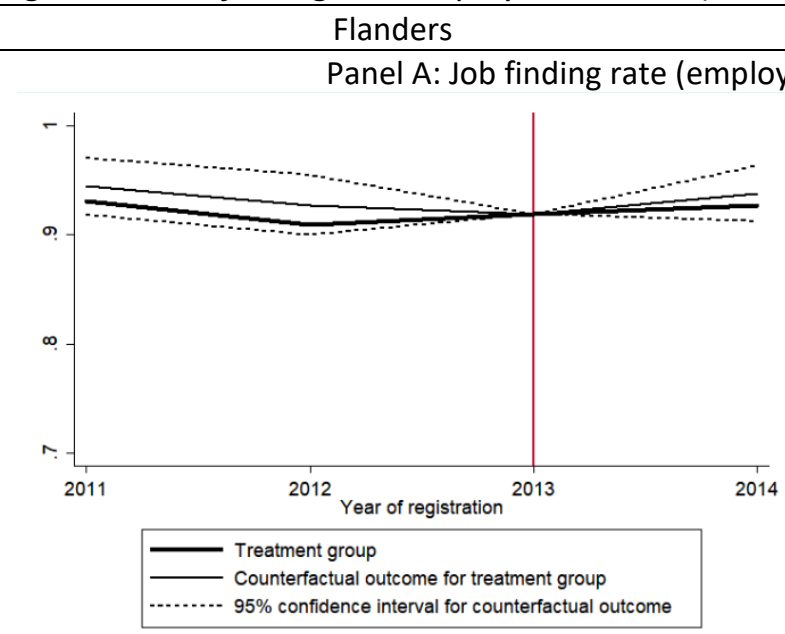

Wallonia

Flanders

the month)

Panel B: Job finding rate (alternative outcomes)

Employed in a temp job

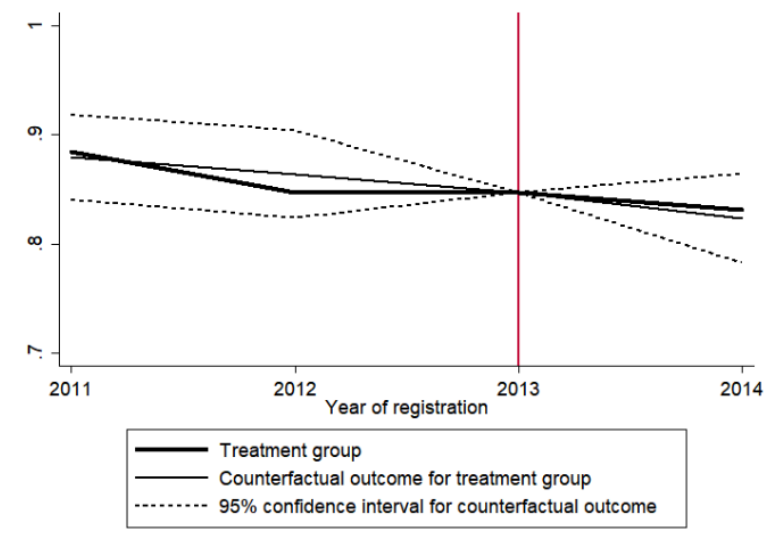

Employed at least 1 day
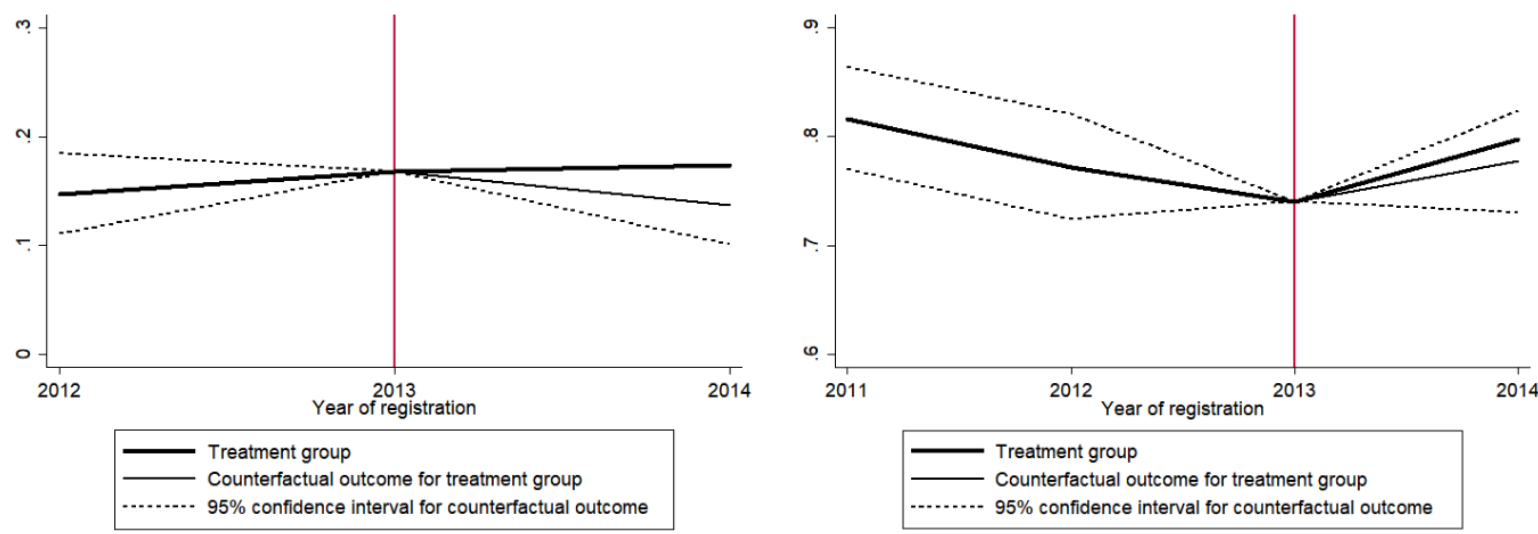

Panel C: Employment rate
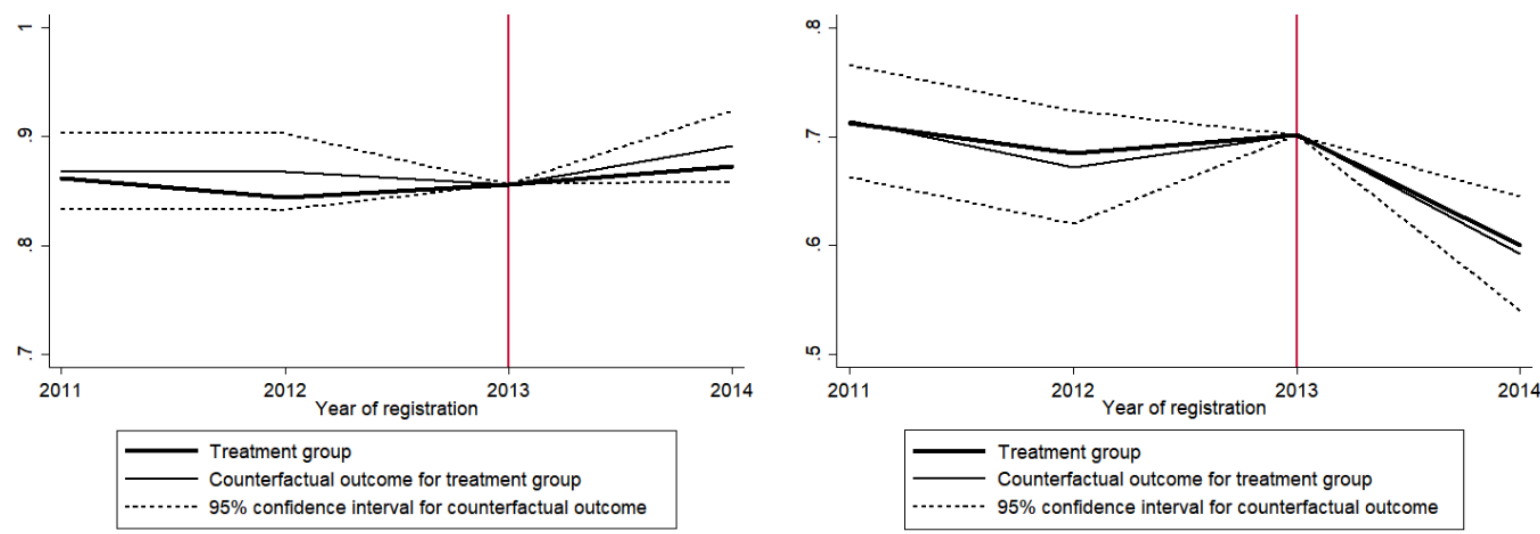

Notes: Treatment group $=24$-year-old job seekers. Control group $=23$-year-old job seekers. Outcomes are measured 12 months after registration at the PES for job seekers who register between June and October after having obtained a master's degree. The vertical line is drawn at the last period before the reform. The thick solid line shows the observed outcome of the treatment group. The fine solid line shows the counterfactual outcome of the treatment group in absence of the treatment. The thin dotted lines are the $95 \%$ confidence interval for the counterfactual path. 
Table A2: Treatment effects on job finding and employment rates (difference-in-differences, no 2011)

\begin{tabular}{|c|c|c|c|c|c|c|}
\hline & \multicolumn{3}{|c|}{ Flanders } & \multicolumn{3}{|c|}{ Wallonia } \\
\hline & 6 months & 12 months & 18 months & 6 months & 12 months & 18 months \\
\hline & \multicolumn{6}{|c|}{ Panel A: Job finding rate (employed on the last day of the month) } \\
\hline \multirow[t]{2}{*}{ Treatment effect } & -0.014 & 0.002 & -0.003 & -0.007 & 0.006 & 0.016 \\
\hline & (0.019) & $(0.014)$ & $(0.011)$ & $(0.024)$ & $(0.021)$ & $(0.018)$ \\
\hline Counterfactual probability & 0.748 & 0.877 & 0.929 & 0.593 & 0.733 & 0.815 \\
\hline Parallel trends: $p$-value & 0.880 & 0.545 & 0.203 & 0.546 & 0.946 & 0.412 \\
\hline \multirow[t]{3}{*}{ Observations } & 9639 & 9639 & 9639 & 7432 & 7432 & 7432 \\
\hline & \multicolumn{6}{|c|}{ Panel B: Job finding rate (alternative outcomes) } \\
\hline & \multicolumn{3}{|c|}{ Employed in a temp job } & \multicolumn{3}{|c|}{ Employed at least 1 day } \\
\hline Treatment effect & $0.033 * *$ & $0.038 * *$ & $0.037^{* *}$ & 0.036 & $0.044^{* *}$ & 0.020 \\
\hline & $(0.014)$ & $(0.015)$ & $(0.016)$ & $(0.024)$ & $(0.022)$ & $(0.020)$ \\
\hline Counterfactual probability & 0.090 & 0.121 & 0.137 & 0.562 & 0.694 & 0.777 \\
\hline Parallel trends: $p$-value & 0.699 & 0.893 & 0.954 & 0.600 & 0.815 & 0.958 \\
\hline \multirow[t]{2}{*}{ Observations } & 9639 & 9639 & 9639 & 7432 & 7432 & 7432 \\
\hline & \multicolumn{6}{|c|}{ Panel C: Employment rate } \\
\hline \multirow[t]{2}{*}{ Treatment effect } & -0.017 & 0.003 & -0.007 & -0.004 & 0.008 & 0.002 \\
\hline & $(0.020)$ & $(0.017)$ & $(0.014)$ & $(0.024)$ & $(0.024)$ & $(0.023)$ \\
\hline Counterfactual probability & 0.711 & 0.813 & 0.880 & 0.536 & 0.615 & 0.599 \\
\hline Parallel trends: $p$-value & 0.936 & 0.381 & 0.189 & 0.316 & 0.667 & 0.638 \\
\hline Observations & 9639 & 9639 & 9639 & 7432 & 7432 & 7432 \\
\hline
\end{tabular}

Notes: Treatment group $=24$-year-old job seekers. Control group $=23$-year-old job seekers. Age is measured at the moment of registration as a job seeker. Control period $=2012-2013$, treatment period $=2014$. Outcomes are measured for job seekers who register between June and October after having obtained a master's degree. The counterfactual outcome is the predicted outcome for the treated in absence of the treatment in the post-reform period. To test for parallel trends, we estimate similar regressions with interaction effects between the treatment groups and year dummies. The parallel trends assumption is rejected if these interaction effects are jointly significantly different from zero in the pre-reform period. The $p$ value of the test is reported. Robust standard errors in parentheses. ${ }^{*} p<0.1,{ }^{* *} p<0.05,{ }^{* * *} p<0.01$. 